\title{
The Mediating Role of Discoursing in Activity
}

\author{
Gordon Wells \\ University of California, Santa Cruz
}

\begin{abstract}
Discoursing, the use of language in interaction with others, plays a part in almost every human activity. Indeed, some have argued that it is discoursing that has made possible the cumulative development of culture over the course of our species' history. Whether or not that is correct, there can be no question that the ability, with the aid of linguistic discourse, to coordinate action, and to reflect together on the relationship between actions and their intended and achieved results, has been an essential contributor. The question is, How should we theorize the relationship between discoursing and the forms of joint activity in which it occurs? At the present time, not only do we not have an answer to this question but the question has hardly been addressed within activity theory. My aim in this article is to offer some suggestions that may help to advance this project. To this end, I put forward and attempt to justify the argument that discourse always functions to mediate the action in which it serves as an operational means and that the distinctions that need to be made between different kinds of discourse can best be handled with the conceptual tools of genre theory.
\end{abstract}

\section{IS DISCOURSING AN ACTIVITY IN ITS OWN RIGHT?}

One of the key principles of activity theory (AT) is that human activity is always mediated by artifacts of various kinds, such that, in Wertsch's (1991) opinion, the basic unit of analysis should be "individual(s)-acting-with-mediational-means" (p. 18). This principle of mediation was first enunciated by Vygotsky $(1978,1999)$, who distinguished two modes of mediation, by tools and by signs. Although the sharpness of his distinction between these two kinds of mediation has since been challenged (Cole, 1996), it remains clear that, in a fundamental way, discursive mediation differs from tool mediation in that instead of being brought to bear directly on the object of action, it takes the form of a transaction between the human participants with respect to the object of their action.

In most work in AT, this distinction has been blurred or ignored, with discoursing generally being seen as just one of the mediating means that contributes to object-oriented action, functioning in conjunction with other artifacts, both material and symbolic. There is perhaps some justification for adopting this orientation when the mediating role of language more generally is considered from both phylogenetic and ontogenetic perspectives. As Donald (1991) convincingly argued, the primary if not the only function of language among the first humans

Correspondence should be sent to Gordon Wells, University of California at Santa Cruz, Department of Education, 1156 High Street, Santa Cruz, CA 95064. Email: gwells@ucsc.edu 
to develop speech would have been to supplement gesture in directing and coordinating joint activity and in the passing on of practical skills from one generation to the next. And it is quite largely through participation in events in which speech is used to direct action that infants are initially inducted into the language of their community (Wells, 1986). In adulthood, too, both at home and at work, speech very often performs similar functions of coordinating the participation of both human and nonhuman "actors" in joint actions, as has been very clearly exemplified with respect to the activity of ship navigation (Hutchins, 1995).

However, such directive or coordinative functions do not constitute the only role of discoursing. In the course of any one day, a typical adult may also take part in a meeting, gossip with colleagues, discuss the news with family or friends, read a story with a child, and answer a phone call soliciting a donation for a charitable organization. As for children, in addition to taking part in some of the same sort of events, they also spend several hours each day in classrooms where language and symbols of other kinds are expected to be the main focus of their attention. On the face of it, these all seem to be actions that are constituted by the discourse rather than simply being mediated by it, and on this basis, it has been suggested that discoursing of these kinds should be treated as an activity in its own right. So just how should discoursing be construed within AT? Is discoursing sometimes simply one mediational means among others and on other occasions an activity in its own right?

Until recently, rather little attention had been given to this question in the writings of activity theorists. However, one particularly interesting exception is Y. Engeström's, $(1991,1999)$ article based on a conference address in which he put forward a model that was intended to explicate the components and internal relations of an activity system. In the published work, he includes two diagrams (Figure 1), which represent first the action of preparing the speech and second that of presenting the speech at the conference. Both of these actions clearly belong to the class of events that are constituted by language. However, in each of these events discoursing is treated as simply one mediational means among others.

In the preparation of the speech, "literature" is shown as the mediating artifact, which is later specified as the writings of Vygotsky, Luria, and Leontiev; the delivery of the speech is then

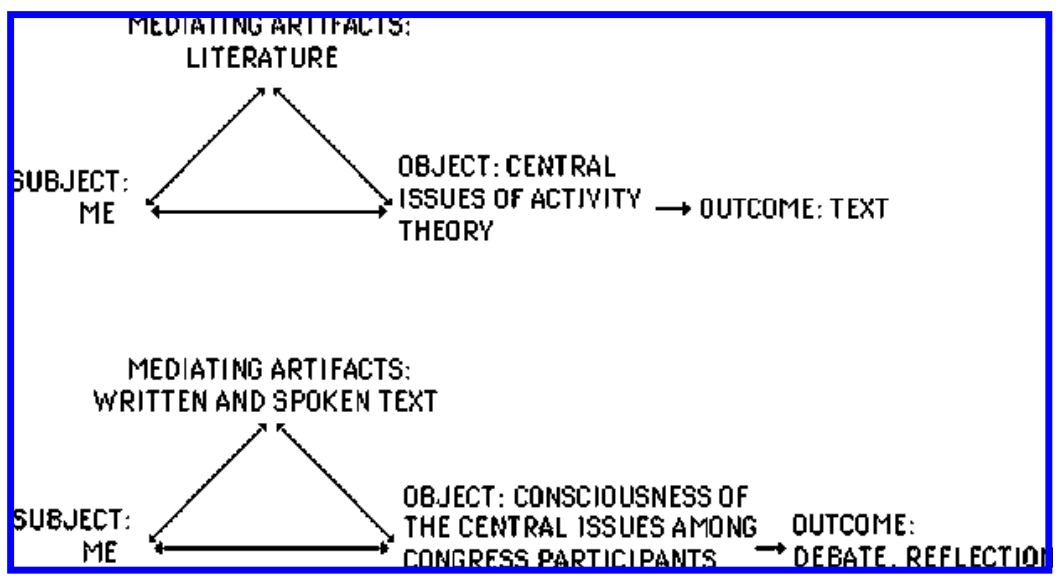

FIGURE 1 Mediation of a Conference Presentation. 
mediated by the prepared text and by the act of speaking. In both of these figures, discourse, whether written or spoken, is represented as directly mediating the subject's action on the object. However, in both cases, the intended outcome is of an "ideal" rather than a material kind (Cole, 1996), and the action involves a transaction between participating subjects rather than on a material object. These important distinctions are not captured in the representations reproduced in Figure 1 or considered in the accompanying text.

In contrast, R. Engeström (1995) treated this issue as central in her investigation of doctorpatient consultations. Drawing on Bakhtinian ideas, she proposed that the discoursing that takes place between doctor and patient should be treated as an action within the activity of meaning construction, with the outcome being what Bakhtin calls a "social language," that is, "a discourse peculiar to a specific stratum of society (professional, age group, etc.) within a given social system at a given time" (as cited in Wertsch, 1991, p. 57). In taking this line, R. Engeström seems to be treating the consultation discourse as an action that realizes a purely linguistic activity (meaning construction), and this view is supported by her statement, "I see a social language corresponding to the level of (collective) 'activity"' (p. 198). At the same time, however, she clearly considers the object of the consultation action to be something other than the discourse itself when she wrote, "in my empirical data from medical consultations, the doctor and the patient encounter one another in order to act on the patient's problem" (p. 197). So here, the object of the action appears to be the patient's problem, which is not purely linguistic, even though it had to be represented linguistically to become the object of their joint action. However, as the analysis proceeds, the action is referred to as "utterance" and, as seen in Figure 2, the object metamorphoses into "previous utterances." As a result, discoursing becomes an activity in its own right, and its function in mediating the action of dealing with the patient's problem disappears.

The problem in this latter case-if it should be so characterized-arises, I suspect, from R. Engeström's very worthwhile attempt to coordinate Bakhtin's insights with the model of the organization of activity proposed by Leontiev (1981). However, although Bakhtin's insights

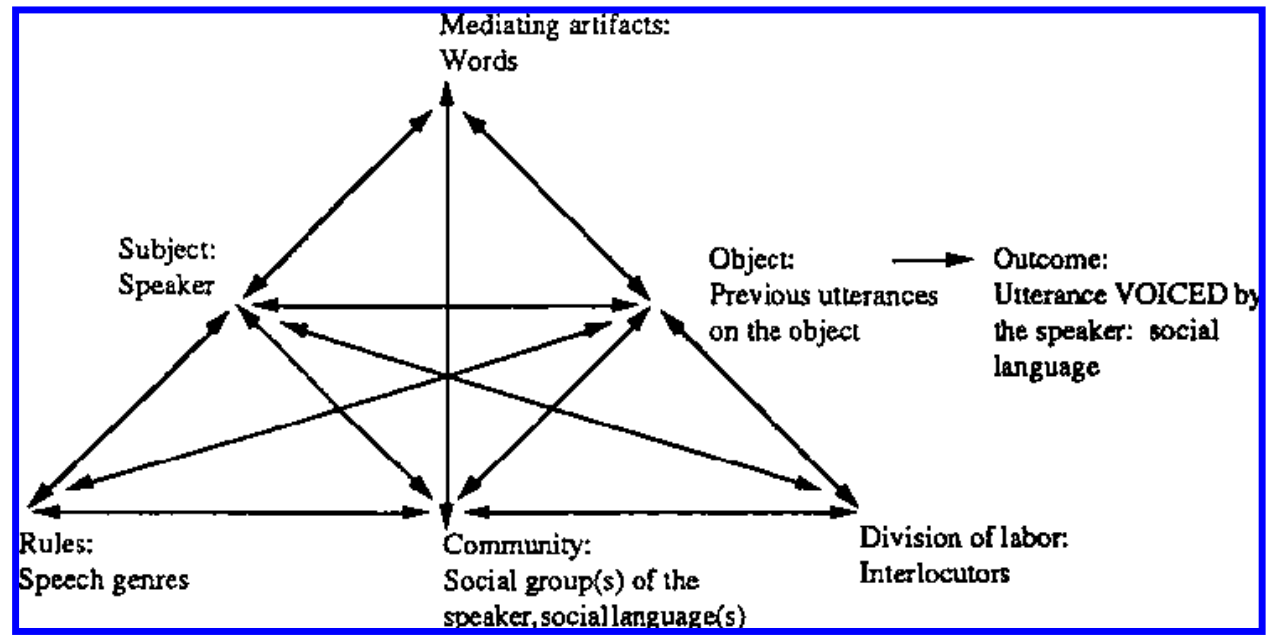

FIGURE 2 Utterance as mediated action. 
are certainly relevant to an attempt to understand how language mediates action, it is difficult to map those insights onto Leontiev's model of activity, because Bakhtin's discussion focused almost exclusively on the domain of language independent of the specific activities in which the discourse played a part. Nevertheless, as I argue, some of his key ideas are essential for a more adequate theory of the relationship between discoursing and activity.

In Leontiev's tristratal model of activity (activity-action-operation), the stratum of action might be glossed as a particular instantiation of a societally organized system of activity that has as motive one of the abiding needs or concerns of human existence in a particular culture at a particular time in its historical trajectory. What distinguishes an action from an activity is its situated, goal-oriented nature and its particularization in terms of the individual participants involved and the artifacts available to them in the place and time in which it takes place. However, actions are typically themselves further organized in terms of subactions, each with its own goal, which frequently have a sequential structure, with the achievement of one goal often being a prerequisite for achieving the goal of the following subaction. Although an action or subaction is conceptualized in terms of its object (both what is acted upon and the outcome that is envisaged), an operation, as Leontiev defined it, is the means judged to be appropriate for attaining the action goal in the conditions that obtain in the situation. He added that operations are routinized ways of doing things that were once actions but now no longer need conscious attention in their performance. It is typically at this stratum of operation that mediational means enter into the model, as using a material tool or a sign system becomes relatively automatic and thus does not distract attention from the object that it is mediating.

Nevertheless, powerful though this model is as an overall conception, it is often difficult to bring it to bear on the analysis of particular events. In part, this is because, as Leontiev himself recognized, many different actions can be instantiations of a particular activity and, conversely, particular actions frequently contribute to more than one activity. For example, earning a living can be achieved in many different ways, which involve quite distinct types of action, any one of which may simultaneously be related to other motives (activities), such as maintaining relations with other members of one's extended family or working for an organization that gives tenure and a guaranteed pension. A further problem is that many actions (e.g., developing a garden) involve so many different subactions and are spread over such long periods that, for analytic purposes, it often seems more appropriate to treat the focal action at each stage as constituting an activity system in its own right.

This issue of determining the scope of the analysis to be carried out and the way in which its constituent parts should be assigned to the three strata is particularly acute when focusing on discourse. On one hand, because discourse typically mediates some action or subaction whose goal is not in itself purely discursive, and because the production of discourse is usually automatic in the sense of not requiring conscious attention, on both these criteria, it seems that it should be treated as an operation. On the other hand, discourse also has its own organization, which, as R. Engeström showed, can be analyzed in terms of different levels or strata. It is this internal organization of discourse that may seem to justify treating it as an independent activity. However, the result of doing so leaves the relationship between discourse as mediational means and the actions that it mediates unresolved.

In what follows, I want to argue for maintaining the operational status of discoursing while distinguishing ways in which it may mediate different types of action. 


\section{ACTION MEDIATED BY ANCILLARY DISCOURSE}

As I have already noted, there seem to be two rather broad but different ways in which discoursing mediates action. In the first, the discourse facilitates (or sometimes hinders) some form of material action, such as building a house, playing a team game, or navigating a ship into harbor. In very general terms, the discourse in these events ensures that all participants are working toward the same goal and are coordinating their individual actions and their use of mediating artifacts to achieve it. In the second manner of mediation, the discourse functions to co-construct a "possible world" (Bruner, 1986) about which participants share and compare their beliefs, evaluations, and intentions to better understand and possibly improve them or to consider courses of action that might follow. I describe this world as a possible one because, unlike the world in which the participants are already engaged in material action in relation to perceptible aspects of the situation, the world to which the participants refer is not necessarily available to sensory perception but is being created and interpreted through the discourse itself. As an initial way of handling this apparent dichotomy, Halliday (1978) proposed that a distinction can be made according to the two different functions of the discoursing, which he referred to as, respectively, "ancillary" and "constitutive."

In the case of ancillary discourse, it is usually easy to see how the discoursing mediates the ongoing action, as its sequential organization is fairly directly related to the subactions involved and to the steps necessary to achieve their respective goals. Hasan's (1985) analysis of shopping for fruit and vegetables provides a very clear example. Here is the text she provides as an example of such a shopping event $(\mathrm{S}=$ salesperson; $\mathrm{C}=$ customer $)$.

1. S: Who's next?

2. C: I think I am.

I'll have ten oranges and a kilo of bananas please.

3. S: Yes, anything else?

4. C: No thanks.

Oh yes. I wanted some strawberries but these don't look very ripe.

5. S: Oh they're ripe all right. They're just that colour kind a' greeny pink.

6. C: Mm, I see.

Will they be OK for this evening?

7. S: Oh yeah, they'll be fine; I had some yesterday and they're very good very sweet and fresh.

8. C: Oh all right then, I'll take two.

9. S: You'll like them cos they're good. Will that be all?

10. C: Yeah, thank you.

11. S: That'll be two dollars sixty-nine please.

12. C: I can give you nine cents.

13. S: Yeah OK thanks. Eighty, three dollars and two is five. Thank you.

Have a nice day.

14. C: See ya.

(adapted from Hasan, 1985, p. 61)

The first point to note about this text is that, although no information is provided about the setting (which is in Australia) or about the nonverbal behavior of the two participants, salesperson and customer, there is no problem in imagining the scene and perhaps even certain 
attributes of the persons involved. This is because the text is part of an action that is familiar in its basic structure the world over, and the text has a structure that corresponds to the sequence of subactions that make up the action. In this text, this basic structure is realized in those moves that are shown in bold type. Hasan described this structure as SR (Sale Request; Turn 2) SC (Sale Compliance; 3-4) - S (Sale; 11) - P (Purchase; 12) - PC (Purchase Closure; 13). These elements, she claimed, are obligatory and must occur in this order; other elements, such as SE (Sale Enquiry; 4-7, 9) and F (Finis; 13-14), are optional. There may also be recursion of certain elements, such as further Sale Enquiries, each followed by Sale Request and Sale Compliance, but the relative ordering of these elements remains constant. ${ }^{1}$

In Systemic Functional Linguistics (SFL), text structures of this kind are referred to as "genres," and research has shown that such genres can be specified for a wide range of service encounters (Hasan, 1985; Ventola, 1987). Not surprisingly, there is considerable similarity between genre structures of this kind and the "scripts" that have been proposed for such wellknown structured actions as eating in a restaurant (Schank \& Abelson, 1977). Thus, although application of the concept of genre has generally been restricted to the analysis of linguistic texts, both spoken and written, it can quite reasonably be extended to the analysis of actions that do not involve discoursing of a linguistic kind. For example, it might be quite appropriately applied to Leontiev's (1981) example of the actions performed by the different groups in his imagined prehistoric hunting activity. This is because the essential defining criterion of the instantiation of a genre is the occurrence of a joint activity in which multiple participants are collaboratively involved. All that is necessary is that, through their spatio-temporal positioning in relation to the object of the action and the use of gestures or some other communicative means, the participants agree on the shared goal of the action and on the stages, or subactions, and the situationally appropriate operations by which the goal is "normally" attained. ${ }^{2}$

In practice, however, most social processes are mediated by discoursing as well as by other artifacts and, in such cases, particularly those involving goods and services, the genre provides what is in effect a template for the sequence of stages that needs to be followed and for the types of utterances that are appropriate at each stage to achieve the participants' shared goal. This is clearly brought out in Hasan's (1985) analysis of the shopping genre where, because the sequential structure of the genre is familiar to the participants, they have no difficulty in producing and coordinating their individual acts - the obligatory elements of the genre-appropriate to their roles in this transaction.

In the case of ancillary genres, of which the shopping genre is one example, where the discourse is mediating some material activity such as the exchange of goods and services, the argument that the discoursing is not an activity in its own right but simply a mediational means will probably meet with little disagreement. The question that now needs to be addressed is whether the same arguments apply to those activities and their action realizations that are actually constituted by discoursing, that is to say, where discoursing appears to be the only action in progress. It is to this that I now turn.

\footnotetext{
${ }^{1}$ Hasan wrote as if this structured sequence is universal. However, there are clearly cultural variations. For example, in many non-Western cultures, bargaining is a normal, if not required, element of the genre of shopping (Mitchell, 1957).

${ }^{2}$ Before the emergence of speech, this constellation of nonverbal modes of communication must have provided the mediational means whereby novices were inducted into the group's activities. Of interest, Roth (2004) has shown that these same modes of communication play a significant role in the learning of science.
} 


\section{ACTION MEDIATED BY CONSTITUTIVE DISCOURSE}

By now, the intended meaning of "ancillary" should be clear. But how exactly should "constitutive" be understood? Essentially, I suggest, what is at issue is the relationship between the discourse and the activity (what Halliday called "social action") in its socially situated context and, in particular, what the discourse participants are actually doing. This is made clear in the following contrastive example offered by Halliday (1978).

In a game of football, the social action is the game itself, and any instructions or other verbal interaction among the players are part of this social action. In a discussion about a game of football, the social action is the discussion and the verbal interaction among the participants is the whole of this social action. (p. 144)

Constitutive discourse, then, in one way or another, is "about" some social action or state of affairs but not itself an integral part of it. The continuation of this quotation clarifies this:

Here the game of football constitutes a second order of "field," 3 one that is brought into being by that of the first order, the discussion, owing to its special nature as a type of social action that is itself defined by language. (p. 144)

In this passage, Halliday focused on the different functions that language performs in these different situations. However, equally important for the argument that I want to put forward is that, in both cases, a "social action" is involved, which implies that there is an object in view and the use of mediational means for its achievement. And in both types of action, I suggest, one of the mediational means is the use of the appropriate genre and the discourse that it engenders.

Support for this argument is provided by the definition of genre in the work of Martin and colleagues, who, in the same SFL tradition, characterize genre as a staged, goal-oriented, social process (Martin, Christie, \& Rothery, 1987). This definition is further explained by Eggins and Slade (1997) as follows:

- Staged: a genre is staged as the meanings are made in steps; it usually takes more than one step for participants to achieve their goals.

- Goal oriented: a genre is goal oriented in that texts typically move through stages to a point of closure, and are considered incomplete if the culmination is not reached.

- Social process: genres are negotiated interactively and are a realization of a social purpose. (p. 56)

In the present context, it needs to be emphasized that this definition applies to the full range of genres. In all situations in which discoursing occurs, including those that involve constitutive discoursing, there is a goal-something that the participants want to "get done"-and there are likely to be a number of stages involved in bringing the action to completion.

\footnotetext{
${ }^{3}$ This might be glossed as "the social action in which the text is embedded" (Halliday, 1978) or, less formally, what the participants are doing at the time.
} 
A clear example of one such constitutive genre is that of the annual general meeting of a large company. Typically, there is a formal agenda, with motions to be debated and voted on. A chairperson controls speaking turns and determines whether each speaker is making a valid contribution or is introducing a topic that is "out of order." The overall goal is to reach agreed-upon decisions for further action, based on the votes cast in favor or against each motion. Important to note here is that, although the discourse is about material actions, these actions are symbolically represented in the wording of the motions and the discussion of them occurs in a place and time that is not part of these actions.

Less formal, but still clearly staged, are department faculty meetings that I have attended. Again, the intended outcome is decisions for future action, but the turn taking is less strictly controlled and digressions are quite frequently caused by members who have their own personal axes to grind. Nevertheless, the overall progress of the meeting is governed by the conventions of the genre, as is apparent from time to time when some member objects that the discussion is either not relevant or inappropriate in some other way.

Although these two examples are not backed up by systematic research, there have been a small number of studies of constitutive discoursing within the SFL paradigm. The first of these that I want to discuss concerns the curriculum genre that Christie (1991) observed in a primary school writing lesson. Rather as in the case of shopping, Christie argued that the lesson she observed, as well as many others like it, had a clear generic structure: Task Orientation (TO) Task Specification (TS) - Task (T). In addition, on the basis of a detailed linguistic analysis of the text of the lesson, she found support for her claim, following (Bernstein, 1986), that a curriculum genre consists of two "orders," the first pedagogical, and the second that of subject content, which is projected by the pedagogical. Christie described this relationship as follows:

In the curriculum genres I have examined, a first order, or pedagogical, register ${ }^{4}$ operates in such a manner that teaching-learning activity is initiated and sustained with a view to carrying forward the activity and achieving the various goals that the teacher has in mind. (p.211)

What is particularly interesting about this latter finding is that the curriculum genre, as she observed it, was in effect a composite genre, in which one part (ancillary) was directly controlling students' actions in the physical space of the classroom (sitting still, not looking out of the window, starting to write) whereas the other was concerned (constitutively) with such actions as discursively remembering, identifying, and explaining. On this account it appears that, in the classroom, students will not carry out such discursively constituted actions unless their participation is under pedagogic control.

The second study is concerned with a very different kind of talk, that of casual conversation (Eggins \& Slade, 1997). If there is any kind of discoursing that seems to have no particular goal, it is the kind that takes place at a dinner party, for example, or in the chat between workers during a lunch break. However, this is far from what Eggins and Slade concluded from their analysis of a range of texts of casual conversation. Among others, they identified genres for telling various types of stories ${ }^{5}$ and for gossiping, which they argued had such clear but not

\footnotetext{
${ }^{4}$ In SFL terms, registers identify the different sets of options from the language's meaning potential that are activated by different situation types.

${ }^{5}$ See also Labov and Waletzky (1967).
} 
necessarily deliberate social purposes as, respectively, evaluating particular experiences and events, and the construction and maintenance of social identities and relationships.

As a final example, I describe a study that two colleagues and I made of our own regular meetings.

\section{PLANNING AND WRITING A CONFERENCE PAPER}

In the year preceding the first meeting of the newly formed International Society for Cultural and Activity Research, Futoshi Hiruma spent 6 months as a visiting scholar at my university. Our joint purpose was to try to gain a better understanding of the relationship between discoursing and activity; this paper is one outcome of our work together. Also taking part in our regular meetings was Tamara Ball, a doctoral student in education. During the 6 months, we met regularly, for about 2 hours each time and, after several meetings, decided to record our discussions to see if an analysis of the transcribed records would help us to better understand the nature of this particular variety of constitutive discoursing.

At the outset, we were not as certain about our beliefs as we would have liked to be, and this was apparent from the early transcripts. But, equally, we were not initially clear how to organize our discussions so that they would be progressive (Bereiter, 1994). Significantly, considerable progress was made on both these counts when we decided first to submit an abstract for a paper to be presented at the International Society for Cultural and Activity Research conference and second to treat the recordings of our discussions as data for empirical investigation. As we (individually) engaged in the drafting of the abstract and in the production and preliminary analysis of the transcripts and then (together) discussed the outcomes of these actions, our discussions became more generically structured and we were able to see how this resulted from a greater shared understanding of our goals.

One of the most difficult aspects of the analysis was to find appropriate terms to describe the subactions by means of which we attempted, through discussion, to advance toward the goals of our joint endeavor. However, we were able to identify some genrelike patterns that characterized each meeting, particularly the later ones. At the macrolevel, each meeting typically started with making proposals for, and agreeing on, an agenda of topics to be addressed. Then, not always entirely systematically, we would discuss the issues relevant to each topic and try to reach a consensual conclusion about them.

At a more microlevel, each agenda item was launched by introducing the topic, either in the form of a position statement or a question about a salient issue. Typically, further positions, either supporting or qualifying, were then put forward and debated, often with attempted justifications by appeal to the work of other scholars. Then at some point, a member would try to ascertain whether we had reached agreement, and either explicitly or implicitly, we would express agreement or decide we had further subissues that first needed to be considered. To illustrate the genre structure that emerged, I include in Figure 3 the flow diagram for the first 15 min of the discussion on February 6, 2005. (The text of this excerpt is included as the appendix.)

Characterized in this way, our discussions may seem to have been more orderly than we experienced them at the time. Two complicating features, in particular, were discovered to be pervasive and characteristic of this genre, as we constructed it. First was the indeterminacy of 

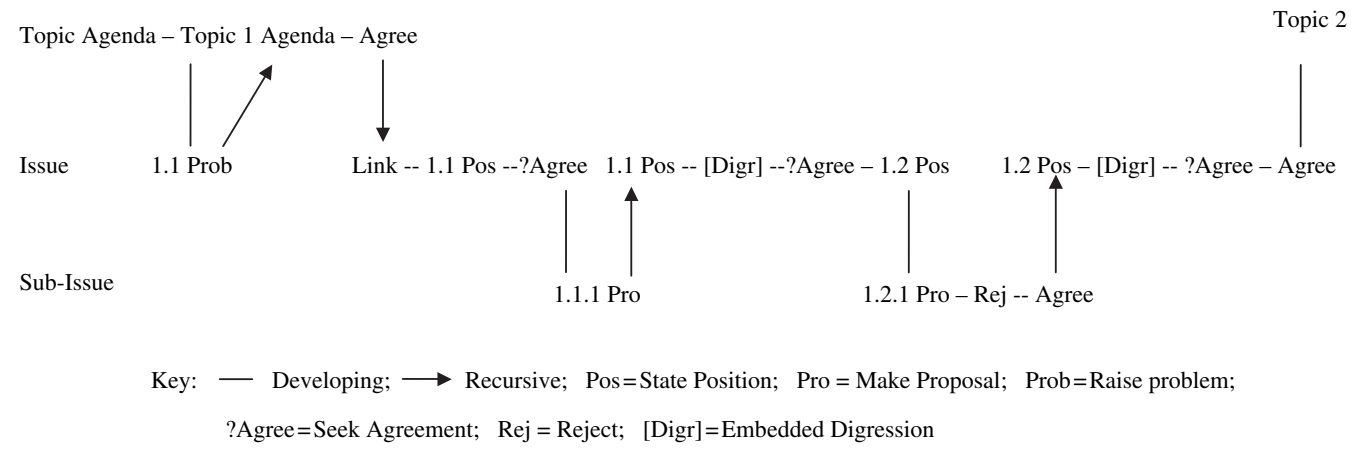

FIGURE 3 Flow Diagram of Discussion 6. Feb. 2005.

the goal(s) of each meeting. Although we became better at setting and adhering to an agenda, the agenda itself had a habit of changing as we proceeded. However, as Lemke (1994) reminded us, this is the nature of any collaborative activity to which people with diverse perspectives and trajectories of scholarship are contributing. Second was the (sometimes annoying) recursiveness of the discussion, as the attempt to reach agreement on one issue or subissue would reengage us with an issue that was supposedly already agreed upon or, alternatively, awaiting more solid grounds on which to make a decision.

Overall, however, the most important outcome of this inquiry was that, although we were initially uncertain as to whether discoursing of the kind we were engaging in should be treated as an independent activity in its own right, our use of the conceptual tool of genre led us to recognize that, like all the other examples of discoursing considered, our discussion was motivated by goals beyond the discourse itself, which were concerned to clarify issues of shared understanding. However, the most significant finding from our analysis of the transcripts of our discussions was that the goals of our actions were both constructed and achieved through discoursing (Hiruma, Wells, \& Ball, 2005).

\section{DISCUSSION}

The goal of the preceding sections of this article has been to show that all forms of discoursing operate in essentially similar ways as mediational means toward the achievement of the goal of the action in progress, whether the object of the action be entities and processes in the material world or symbolic representations of those entities and processes. This is so, I have argued, because whatever type of action is involved, its goal can only be achieved if the participants organize their contributions according to the "rules" of the genre that is most appropriate for their purpose in their shared situation. Although these genres might, following Halliday (1978), be distinguished in terms of the ancillary or constitutive role of discoursing in relation to the object (goal), in every case they function as mediating artifacts in achieving the intended outcome of the action.

In invoking genre as the key construct in my argument, there is clearly some resonance with Bakhtin's (1986) claim that "we speak only in definite speech genres ...Even in the most free, the most unconstrained conversation, we cast our speech in definite generic forms" (p. 78) As 
he further explained, "All the diverse areas of human activity involve the use of language. ... [Our] utterances reflect the specific conditions and goals of each such area not only through their content (thematic) and linguistic style, but above all through their compositional structure" (p. 60).

However, Bakhtin's use of the term speech genre cannot be completely equated with the use of genre in SFL. Although both Bakhtin and systemic functional linguists are concerned with the relationship between discoursing and activity, Bakhtin focuses on the influence of the situation on the form of the speech genre, whereas Halliday is quite clear that the relationship between situation and text is reciprocal: The participants' interpretation of the situation largely determines what they say, but equally what they say affects their interpretation of the situation. Furthermore, although Bakhtin conflates content, style, and compositional structure under the single construct of "speech genre," in SFL a distinction is made between register, which accounts for the predictable relationship between the situation and the semantic features of the text, and genre, which, as Hasan illustrated, is superordinately concerned with its staging or compositional structure (see Hasan, 1992, for a fuller discussion). Nevertheless, recent work in SFL genre theory, by Hasan, Martin, and their colleagues, has made use of Bakhtin's insights and has begun to develop a systematic specification of the structures of different genre types.

From this work it has becomes apparent that the initial distinction made by Halliday (1978) between ancillary and constitutive discoursing, although useful conceptually, is an oversimplification of actual practice. The first and most obvious complication is that many interactions involve more than one genre, as when a shopper discusses the weather or current events in the course of a purchasing action. (See also Christie, 1991, for a discussion of the curriculum genre.) A second issue is that the distinction between ancillary and constitutive discoursing is not as clear-cut as Halliday suggested. Taking the football example from earlier, at various points before and during the game, the coach discusses strategy with the entire team and perhaps also with one or more individuals; he will probably also shout from the sidelines. Although the latter might fit Halliday's argument that "any instructions or other verbal interaction among the players are part of this social action" (p. 144), it is not so clear that the strategy talk before the team leaves the dressing room is entirely part of the "social action" of the game itself.

However, the most difficult issue is that of determining what goals are involved in any action in which discoursing plays a part. The problem is that participants rarely announce their goals, expecting others to be able to deduce them from the situation and from the genre form they adopt. Where the participants are brought together by a material action that requires their coordinated acts, it is relatively easy to specify their joint goal (although they might not all agree on any particular formulation of it), but there are many forms of joint action where the goal is not nearly so apparent and where the participants may not all have the same goals. This can be seen rather clearly in the following episode from a Grade 3 classroom, in which the children, working in groups, were carrying out self-chosen inquiries under the umbrella theme of winter.

In this episode, Marilda, a Portuguese Canadian child who is repeating Grade 3, has made a model weather vane, ${ }^{6}$ of which she is very proud. After waiting for some minutes, she manages

\footnotetext{
${ }^{6}$ Marilda has made the model, following instructions found in a book, by first securing a rectangle of stiff paper to one end of a drinking straw and a paper clip to the other end, and then putting a pin through the midpoint of the straw into the eraser on the end of a pencil with a bead between straw and eraser.
} 
to gain her teacher's attention, and the teacher invites her to explain the working of the weather vane to several other children whom the teacher gathers round. ${ }^{7}$

Marilda: It's here, my windfinder.

Teacher: $\quad$ OK, so here's your windfinder.

That's a good name for it, isn't it?

Marilda: (demonstrates by blowing to make her windfinder work)

Eric: $\quad$ Oh Miss-

Teacher: Eric, have you seen this windfinder?

Eric: $\quad$ Yes, last year we were studying about it.

Teacher: Mm. (to Marilda) Can you- can you explain- like. Can you explain how it works?

Eric: $\quad$ Yes, I know how it works.

Teacher: (to Eric) Oh excuse me. I was really speaking "to Marilda "(to Marilda) Can you explain it? (to Maria) Maybe you'd be interested in this. Do you want to come over here? (putting her arm round her to bring her closer) (Jacinta and Maggie also join the group.)

Marilda: When you- when the wind blows. it's trying to find the wind.

When the wind blows this points to which direction it's coming from. (pointing to the pointer on her wind finder)

Jacinta: $\quad$ Yeah like- (she takes the windfinder and demonstrates)

Marilda: See, it's pointing round to you.

Teacher: Why's it pointing to you? (referring to Jacinta, but addressing the question to the whole group)

Eric: $\quad$ Because she's the one who blew.

Marilda: And if you keep on- (takes back windfinder from Jacinta) (Maggie tries to blow)

Jacinta: You have to blow hard. (Maggie blows hard)

Marilda: OK now blow again. (Maggie blows again)

It stays in the same spot cos- $\underline{\text { cos the wind's- }}$

Teacher: Why?

Jacinta: $\overline{\text { Cos }}$ it needs a big surface to blow on. to push it.

Teacher: $\quad$ Come on. (encouraging Marilda to continue)

Marilda: Cos the- cos the wind's blowing that direction and it-

Maggie: $\quad$ No. why did it go?

Marilda: - it's not coming in a different way.

Eric: Because it doesn't have a piece of paper over here. (pointing to the end of the straw with the paperclip)

Teacher: What would happen if you had a piece of paper over there?

Marilda: It'd turn around?

Jacinta: $\quad$ Because it needs a big surface to blow on to push it.

\footnotetext{
${ }^{7}$ In the following transcript, adjacent passages that are underlined were spoken simultaneously, a period indicates a perceptible pause, and a hyphen indicates an interruption or a restart.
} 
Teacher: $\quad$ So it's-

Eric: $\quad$ And that's a big surface.

Teacher: So it's got something to do with the surface of the paper?

Children: Yeah.

Teacher: And the air?

Eric: $\quad$ Mm.

Marilda: And the- this thing. maybe (pointing to the bead)

Teacher: $\quad$ Oh and-

Eric: $\quad$ It's the needle.

Jacinta: No I think it's got to turn-

Eric: $\quad$ It's the needle it's the needle that- well not the needle but the, the straw. it's the straw has the hole.

Marilda: $\quad$ This makes it-

Eric: $\quad$ The straw has the hole and the hole like causes it to. to make a wiggly turn.

Teacher: $\quad$ Yes. (somewhat doubtfully)

Marilda: No it's this that makes it-

Teacher: Which? The bead?

Marilda: Yeah.

Teacher: The bead. you think the bead is very important?

Marilda: Yeah.

Teacher: Why? Why do you think that's important?

Jacinta: Let's try it without the bead.

Marilda: $\quad$ Cos the-

Teacher: (to Jacinta) That's a good idea. that- that would. be a way of finding out if it's really important.

(to Marilda) First, why do you think the bead's important?

Marilda: Well .., some machines they have a-

Eric: $\quad$ It's a nuisance. (referring to the bead)

Marilda: $\quad$ - the little round things.

Eric: $\quad$ Yes but some machines don't have them.

Teacher: Ballbearings? You mean ballbearings.

Marilda: $\quad$ Yeah. so maybe like it might make it- might help by spinning it. like spinning.

Teacher: It's got something to do with the spinning and then making it easier to spin. I like your idea, Jacinta. that's a very interesting idea, taking the bead out. I don't know whether Marilda would. want to do that now or not.

Jacinta: $\quad$ - want to-

Marilda: OK, I'll try it.

(Marilda and Jacinta go away to try the experiment)

In this particular episode, which from beginning to end lasts no more than 2 min, it is quite apparent that the various participants have different goals-at least to begin with. Marilda initially wants to gain the teacher's interest and approval but then, at the teacher's request, she tries to explain how the windfinder works; Eric seems to want to let the teacher know how 
knowledgeable he is; and Jacinta, who has been working with Marilda, joins the group out of solidarity and quickly becomes involved in the action of explaining. Toward the end, she proposes a further experiment. Recognizing all these different goals, the teacher has to make a series of on-the-spot decisions. From her behavior, it seems reasonable to attribute to her a number of simultaneous goals: to show her interest in Marilda's artifact; to get Marilda to externalize her understanding of the artifact in a coherent explanation and thereby to boost her self-confidence as a successful student; to include the other children in the action of explaining while keeping the focus on Marilda's contribution; to use Jacinta's suggestion as a means of inviting Marilda to pursue her interest in the windfinder by testing her hypothesis about the function of the bead.

While demonstrating the teacher's consummate skill in managing a particularly complex learning-and-teaching opportunity, this episode also shows that the notion that the goals of action are predetermined is only plausible from the post hoc, synoptic perspective of an analyst who views the event from outside. ${ }^{8}$ For the participants, goal setting is an ongoing process that is emergent as the action proceeds (Lemke, 1994); for this reason, as Eggins and Slade (1997) advised, "The generic perspective needs to be complemented by a dynamic analysis that focuses on the unfolding of the talk, move by move" (p. 273).

From having followed this advice with respect to the preceding episode, it seems clear that participants in discursive interaction are frequently working toward multiple simultaneous goals (albeit not all at a conscious level). Depending on the circumstances, these might include at least the following: negotiating interpersonal relationships, making their contributions relevant and effective in the immediate discourse context, negotiating the emergent goals of successive subactions in the light of the overall action goal, monitoring progress toward these goals, and taking corrective action, as necessary. Moreover, it seems likely that the need to manage similar simultaneous goals is also characteristic of joint action that proceeds without the need for any form of specifically linguistic interaction.

If accepted, the preceding tentative conclusions have far-reaching implications for the way we think about, and represent, all forms of joint action.

\section{SOME TENTATIVE CONCLUSIONS ABOUT DISCOURSING AND ACTIVITY}

As is well known, Vygotsky (1978) placed great emphasis on the mediating role of language in human development and behavior, considering it to be the "tool of tools." As he wrote,

The invention and use of signs as auxiliary means of solving a given psychological problem (to remember, compare something, report, choose, and so on) is analogous to the invention and use of tools in one psychological respect. The sign acts as an instrument of psychological activity in a manner analogous to the role of a tool in labor. (p. 52)

But he also made a crucial distinction between "signs" and "tools" in terms of their functions in mediating action:

\footnotetext{
${ }^{8}$ Clearly, this complex negotiation of goals does not easily fit Christie's description of the instances of the classroom genre she observed.
} 
The tool's function is to serve as the conductor of human influence on the object of activity; it is externally oriented. The sign, on the other hand, changes nothing in the object of a psychological action. It is a means of internal activity aimed at mastering oneself; the sign is internally oriented. (p. 55)

However, as Vygotsky (1981) frequently emphasized, "The word's first function is its social function" (p. 158), that is to say, to mediate interaction between people in the course of their joint activity. Indeed, this is the intermental source from which the individual appropriates the social signs that come to be the means of intramental action.

On the other hand, in activity theory, with its emphasis on the object orientedness of action, the interactional function of language in mediating activity has tended to be subsumed under its directive function. Thus in the model of action developed by Y. Engeström $(1991,1999)$ both sign-mediated and tool-mediated action are represented by the same triangle (see Figure 1), that is, as a means the subject uses to act on the object of the action. For some forms of activity this may seem to be perfectly adequate. A prototypical example might be the members of a community engaged in barn raising, where the contributions of individual participants are more or less interchangeable. In such situations, an utterance by the leader of the group asking another to carry out some subpart of the action might reasonably be seen as an operation by which means the speaker acts on the receiver to recruit that individual as a further (instrumental) means of mediating the overall ongoing action.

However, if we reconsider the shopping transaction previously described, it is clear that in this event, the participants are not interchangeable, nor is either using the other as a mediational means in an instrumental fashion. Although both desire the same outcome-the exchange of goods for money-their contributions to the transaction are reciprocal rather than equivalent and the outcome is negotiated between them. And the same would certainly be true of the actions in which discoursing plays a constitutive role.

To represent the relationship among the participants in any activity system that involves transactions of the kind just described requires a different representation from that in Figure 1 or its expanded version (Y. Engeström, 1991, 1999). What is needed is a way of representing the fact that, as they act together on the object, their joint action is mediated by the discursive interaction between them. Furthermore, the mediational means - the discoursing - is a process, emergent and coconstructed over the course of the interaction. Although the genre that structures the interaction preexists the action as a semiotic tool available to members of the community, this too has to be negotiated as the action proceeds.

In a previous study (Wells, 2002), I proposed such an alternative representation, which is reproduced in a somewhat revised form in Figure 4. While retaining all the essential elements in Engestrom's model, I have made three significant changes in the layout. First, I have enclosed all the upper part of the diagram with a dotted line. The resulting "circle" is intended to represent the fact that any action is situated in a particular time and place. This specific situation provides affordances for, and also places constraints on, how the action will be undertaken. In particular, as Leontiev (1981) pointed out, it affects the operations by means of which the action will be realized.

The second change is the inclusion of two Subjects (more could be represented in a threedimensional representation), who are shown in a transaction with each other, and the Object, which is represented by the black circle in the center. This transaction is shown by the lower 


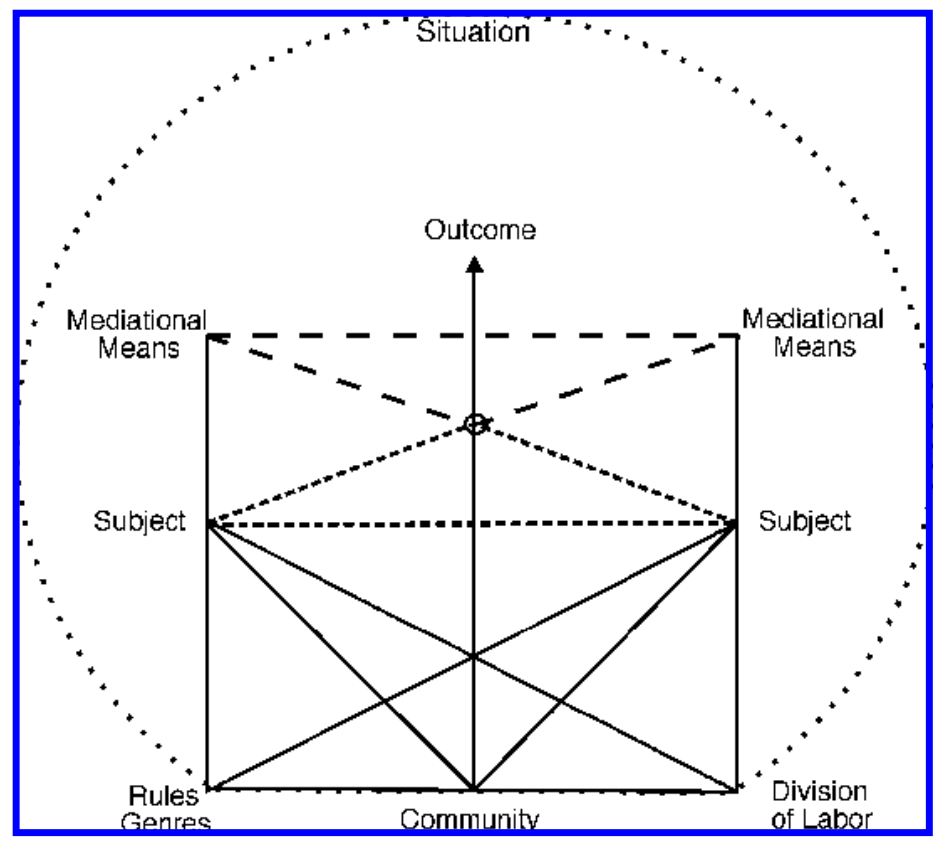

FIGURE 4 A transactional model of discoursing in an activity system.

broken-lined triangle, in which a genre appropriate to the action structures the discoursing. Third is the addition of the level of Operation, which is represented by the upper broken-lined triangle. Because more than one subject is involved in the transaction, the operation involves all of them in codeploying their language resources in the construction of the genre-structured text that mediates the achievement of the goal of their joint action.

Finally, it is important to recognize that the Outcome(s), depending on the object of the action, can be of various kinds: transforming the material world, transforming the "virtual" intermental world, and transforming the intramental worlds of the participants. The outcomes also include the text that is coproduced in the discoursing. When this is recorded in some way, as in writing or the use of a recording device, it can serve as an artifact in mediating further actions.

\section{CONCLUSION}

My aim in this article has been to put forward and justify two claims about the role of discoursing in activity. First, the discoursing always functions as a mediational means in achieving the goals of the action in which it occurs. Depending on the nature of the action and the object involved, the goal may be partly or wholly of an intermental kind, but the operations by which it is achieved always have a material embodiment, in speech and/or in acts that utilize material artifacts. It is also important to recognize that goals are often emergent in the action, particularly when the action is wholly mediated by constitutive discourse. 
Second, I have argued that, just as joint material action is typically structured by cultural scripts, which may be modified in the situation, so the discoursing that mediates joint action is structured by discourse genres, which are also cultural artifacts (Bakhtin, 1986). Furthermore, as Vygotsky (1981) argued, appropriating these discourse genres provides a resource for individual thinking, as this is mediated by inner speech or another semiotic modality.

In sum, I am arguing that discoursing should not be considered as an activity in its own right but as an operation using linguistic resources that are variously drawn on to coconstruct the appropriate genre for the action that the discoursing mediates. The fact that discoursing has levels of organization - utterance functions, semantics, lexico-grammar, and phonology—does not mean that it is not functioning as an operation. After all, an operation such as driving a car as part of a shopping action also has levels of organization (Leontiev, 1981). The point is that in both cases, the operation rarely requires conscious attention, as it is sufficiently well practiced to be relatively automatic.

The advantage of this proposal, I believe, is that it clarifies what it means to call discourse a mediational means, even when, as in Y. Engeström's conference presentation that was referred to, or indeed in this article, the action is realized entirely through discoursing. At the same time, however, it would seem to follow from the arguments developed here that, as most actions are "joint actions," they are highly likely to be mediated by means that involve transactions among the participants, including discursive negotiation of how they should be carried out as well as reflexive monitoring of their progress (W-M. Roth, personal communication, August 11, 2006). And this, in turn, puts in question the tendency to consider action as simply object oriented and to represent it as unidirectional. However, this is clearly an issue that needs much further discussion. It is in this dialogic spirit that, following Bakhtin (1986), this article, as with any utterance, however long, anticipates a responding utterance, whether of an extending or qualifying kind.

\section{REFERENCES}

Bakhtin, M. M. (1986). Speech genres and other late essays (Y. McGee, Trans.). Austin: University of Texas Press.

Bereiter, C. (1994). Implications of postmodernism for science, or, science as progressive discourse. Educational Psychologist, 29, 3-12.

Bernstein, B. (1986). On pedagogic discourse. In J. Richardson (Ed.), Handbook of theory and research in the sociology of education (pp. 205-239). New York: Greenwood.

Bruner, J. S. (1986). Actual minds, possible worlds. Cambridge, MA: Harvard University Press.

Christie, F. (1991). Pedagogical and content registers in a writing lesson. Linguistics and Education, 3, $203-224$.

Cole, M. (1996). Cultural psychology: A once and future discipline. Cambridge, MA: The Bellknap Press of Harvard University Press.

Donald, M. (1991). Origins of the modern mind: Three stages in the evolution of culture and cognition. Cambridge, MA: Harvard University Press.

Eggins, S., \& Slade, D. (1997). Analyzing casual conversation. London: Cassell.

Engeström, R. (1995). Voice as communicative action. Mind, Culture, and Activity, 2, 192-215.

Engeström, Y. (1991). Activity theory and individual and social transformation. Activity Theory, 7/8, 6-17.

Engeström, Y. (1999). Activity theory and individual and social transformation. In Y. Engeström, R. Miettinen, \& R. L. Punamäki (Eds.), Perspectives on activity theory (pp. 19-38). Cambridge, England: Cambridge University Press.

Halliday, M. A. K. (1978). Language as social semiotic: The social interpretation of language and meaning. London: Arnold. 
Hasan, R. (1985). The structure of a text. In M. A. K. Halliday \& R. Hasan (Eds.), Language, context and text: Aspects of language in a social-semiotic perspective (pp. 52-69). Geelong, Australia: Deakin University.

Hasan, R. (1992). Speech genre, semiotic mediation and the development of higher mental functions. Language Sciences, 14, 489-528.

Hiruma, F., Wells, G., \& Ball, T. B. (2005, September). The problem of discoursing in activity. Symposium conducted at the meeting of the First Conference of the International Society for Cultural and Activity Research, Seville, Spain.

Hutchins, E. (1995). Cognition in the wild. Cambridge, MA: MIT Press.

Labov, W., \& Waletzky, J. (1967). Narrative analysis: oral versions of personal experiences. In J. Helm (Ed.), Essays on the verbal and visual arts (pp. 12-14). Washington, DC: University of Washington Press.

Lemke, J. L. (1994). Discourse, dynamics, and social change. Cultural Dynamics, 6, 243-275.

Leontiev, A. N. (1981). The problem of activity in psychology. In J. V.Wertsch (Ed.), The concept of activity in Soviet Psychology (pp. 37-71). Armonk, NY: Sharpe.

Martin, J. R., Christie, F., \& Rothery, J. (1987). Social processes in education: A reply to Sawyer and Watson. In I. Reid (Ed.), The place of genre in learning: Current debates (pp. 58-82). Geelong, Australia: Deakin University, Centre for Studies in Literary Education.

Mitchell, T. F. (1957). The language of buying and selling in Cyrenaica: A situational statement. Hesperis, 26, 31-71.

Roth, W. M. (2004). Gestures: The leading edge in literacy development. In W. Saul (Ed.), Border crossing: Essays on literacy and science (pp. 48-70). Newark, DE: International Reading Association \& National Science Teachers Association.

Schank, R. C., \& Abelson, R. P. (1977). Scripts, plans, goals and understanding: An inquiry into human knowledge structures. Hillsdale, NJ: Lawrence Erlbaum Associates.

Ventola, E. M. (1987). The structure of social interaction: A systemic approach to the semiotics of service encounters. London: Frances Pinter.

Vygotsky, L. S. (1978). Mind in society: The development of higher psychological processes. Cambridge, MA: Harvard University Press.

Vygotsky, L. S. (1981). The genesis of higher mental functions. In J. V. Wertsch (Ed.), The concept of activity in Soviet psychology (pp. 144-188). Armonk, NY: Sharpe.

Vygotsky, L. S. (1999). Tool and sign in the development of the child. In R. W. Rieber (Ed.), The collected works of L. S. Vygotsky, Vol. 6: Scientific legacy (pp. 3-68). New York: Kluwer Academic/Plenum.

Wells, G. (1986). The meaning makers: Children learning language and using language to learn. Portsmouth, $\mathrm{NH}$ : Heinemann.

Wells, G. (2002). The role of dialogue in activity theory. Mind, Culture, and Activity, 9, 43-66.

Wertsch, J. V. (1991). Voices of the mind: A sociocultural approach to mediated action. Cambridge, MA: Harvard University Press. 